\title{
Is the groundwater reservoir linear? Learning from data in hydrological modelling
}

\author{
F. Fenicia $^{1,2}$, H. H. G. Savenije ${ }^{2}$, P. Matgen ${ }^{1}$, and L. Pfister ${ }^{1}$ \\ ${ }^{1}$ Public Research Center - Gabriel Lippmann, 41 rue du Brill, 4422, Luxembourg \\ ${ }^{2}$ Water Resources Section, Faculty of Civil Engineering and Geosciences, Delft University of Technology, P.O. Box 5048, \\ 2600 GA Delft, The Netherlands
}

Received: 2 August 2005 - Published in Hydrol. Earth Syst. Sci. Discuss.: 30 August 2005

Revised: 25 November 2005 - Accepted: 20 December 2005 - Published: 22 February 2006

\begin{abstract}
Although catchment behaviour during recession periods is better identifiable than in other periods, the representation of hydrograph recession is often weak in hydrological simulations. Among the various aspects that influence model performance during low flows, in this paper we concentrate on those more inherently related to the modelling, such as the development of a suitable model conceptualization, and the choice of an appropriate calibration strategy. In this context we develop a methodology where the calibration procedure is combined with an iterative process of model improvement, to obtain an optimal model configuration that performs well both during low flows and high flows. The methodology starts by calculating a synthetic master recession curve that represents the long-term recession of a given catchment. Subsequently, using a simple reservoir model, we determine the storage-discharge relation that simulates the slow hydrograph component. This relation is determined without making any a-priori assumption on its form and is inferred from discharge data available through an iterative process. Next, high flow related parameters are recalibrated separately, to avoid that the simulation of low discharges is neglected in favour of a higher performance in simulating peak discharges. This methodology is applied on several catchments in Luxembourg, and as a result we determined that in all catchments except one (where human interference is high) within the chosen model structure a linear reservoir describes best the observed groundwater behaviour. This result is used to trigger a discussion as to the general suitability of the use of a linear groundwater reservoir in hydrological modelling.
\end{abstract}

\footnotetext{
Correspondence to: F. Fenicia

(fenicia@lippmann.lu)
}

\section{Introduction}

During recession periods, catchment response is more regular and better identifiable than during or shortly after rainfall events. Streamflow under dry weather conditions is generally considered to be sustained by groundwater. Groundwater flow is related to storage properties and subsurface hydraulics rather than concentration times and pathways of the surface watershed (Wittenberg, 2003). Therefore it is less affected by the variability of those factors that influence surface water flow, such as the typology of a rainfall event or the seasonal variation of land cover. Finally, data quality and reliability improves with low discharges, allowing a better control on catchment behaviour.

While these considerations would lead to the conclusion that low flow events should be easily predictable, their representation is often weak in hydrological simulations. Among the various reasons that can justify bad model performance during low flows we identify the following: 1) inappropriate process conceptualization; 2) unsuitable calibration strategy; 3) unreliable data (e.g. wrong rating curves, change in river cross sections, low flow measures in temporary frozen rivers). While the last problem lies beyond the domain of modelling, the first two are inherently related and concern any modelling action. Model structures and parameterizations are inherently uncertain when they are based on an apriori representation of the natural system. When a flawed conceptualization combines with calibration strategies that favour an accurate representation of peak flows, model structural inadequacies manifest themselves as a biased representation of other aspects of the simulation, such as flow recession and low flows (Gupta et al., 1998). In this context, improvement of model performance should be achieved through improving model conceptualization and calibration strategies.

Model structural uncertainties can be reduced if model conceptualization, instead of being a-priori defined, is

Published by Copernicus GmbH on behalf of the European Geosciences Union. 
flexible and can be adjusted in response to observations. In conceptual modelling, this has led to the development of generic frameworks where the model structure is inferred from data or from field evidence. The top down approach (Klemeš, 1983; Sivapalan et al., 2003), the dominant process concept (Grayson and Blöschl, 2000), and the development of flexible box models (Wagener et al., 2001) are some examples in this field.

The need of appropriate calibration strategies has led to the conclusion that the calibration problem should be analysed through a multi-objective approach (Gupta et al., 1998). Different objectives define model performance with respect to different aspects of the simulation, and can be used to better fit the model output to specific characteristics of the recorded signal (Boyle et al., 2000; Hogue et al., 2000) or to force the various processes simulated by the model to match different measured variables (Uhlenbrook and Leibundgut, 2002; Seibert and McDonnell, 2002).

In this paper, we identify a calibration strategy that looks for a conceptualisation and parameterisation that considers the dynamics of high and low flows separately. This result is obtained through a multi-step calibration approach, where parameters are calibrated in separate stages according to multiple objectives (Hogue et al., 2000). The methodology initially calibrates model parameters with bias to low flow, and subsequently recalibrates some parameters (those related to high flow simulation) with a bias towards fitting the high flows. The interaction between the mechanisms that generate high and low flow is dealt through iteration.

While fitting the model to the data, we make use of a general non-linear recession equation, and iteratively improve the parameterization of the groundwater-generating component of the conceptual model. Recession characteristics for a given catchment are derived through the calculation of a master recession curve (MRC) from a set of recession segments. The MRC is then used to derive a storage-discharge (S-D) relation to describe the behaviour of a reservoir that conceptualizes the integrated response of the groundwater processes. This relation is also affected by the flux entering the reservoir, which is a-priori unknown. Therefore the S-D relation is adjusted iteratively during the first calibration stage.

The model adaptation to field data can be regarded as a combination of a bottom-up and top-down approach (Sivapalan et al., 2003), in the sense that within an a-priori defined model structure, the parameterization of the groundwater model component is inferred from the data, instead of being previously specified.

The attempt to adapt a model structure to recession data has already been performed in previous studies. Ambroise et al. (1996) tested the application of alternative forms of recession curves to TOPMODEL; working on the same model, Lamb and Beven (1997) describe the derivation of an appropriate recession curve by analysing recession data; Moore (1997) applies several storage-outflow models to recession analysis.
Following the work of Lamb and Beven (1997), the S-D relation is inferred from the data, instead of being a-priori determined. Although these authors concentrated on recession analysis per-se, in the present paper we present a combined modelling-calibration methodology for the complete rainfall-runoff process. The procedure has been applied in eight catchments in Luxemburg, which will be used as illustrations.

\section{Study area}

The study area comprises eight catchments in Luxembourg. In the central and southern part of Luxembourg, the lithology mostly consists of an alternation of marls, sandstone and limestone. This alternation strongly influences the relief of the area, which is mostly characterized by cuestas. The landscape is characterized by gently sloping areas of marls that alternate with deep valleys cut into sandstone or limestone formations. The northern part of Luxembourg belongs to the Ardennes massif; lithology in this area is mainly represented by compact metamorphic rocks like schist and phylite.

Marls can be considered to be impervious and highly responsive to rainfall. Those formations have little storage capacity, therefore, in those areas, the streamflow is concentrated in rainfall periods, and is very low or absent during prolonged dry weather periods. Streamflow is sustained by saturated throughflow, occurring at the interface between the soil and the underlying bedrock layer.

The response of shist depends on the water content of the basin. During the wet season the weathered zone quickly saturates, resulting in a more pronounced response to rainfall than during the dry periods. Depending on the development of the weathered zone, schist sustains discharge during the dry period. Deep percolation seldom occurs due to discontinuities in the rock mass.

Sandstone formations are highly permeable allowing deep percolation, and are located on top of a confining marl layer. In those areas, the streamflow is mainly sustained by groundwater flow, which occurs either by channel incision of the groundwater table or as springs at the contact zone between the sandstone and the marl. With respect to the other formations, sandstone areas are characterized by a dampened response to rainfall.

The sub-basins chosen represent a variability of basin sizes, geological conditions, physiographical properties, as well as the availability and quality of streamflow data. The main physiographical characteristics of the sub-basins and the major geologic units are summarized in Table 1. The locations of the catchments are shown in Fig. 1. Some of the catchments are nested, in particular the Attert-Useldange catchment includes the Schwebich-Useldange catchment, and the Alzette-Pfaffenthal catchment includes the AlzetteHesperange and the Petrusse-Luxembourg catchments. 
Table 1. Physiographic characteristics of the selected catchments. SH: schists, SS: sandstone, MR: marls, LS: limestone.

\begin{tabular}{llcccccl}
\hline Catchment & Outlet & $\begin{array}{c}\text { Area } \\
{\left[\mathrm{km}^{2}\right]}\end{array}$ & $\begin{array}{c}\text { Cultivated } \\
\text { land }(\%)\end{array}$ & $\begin{array}{c}\text { Grassland } \\
(\%)\end{array}$ & $\begin{array}{c}\text { Forested } \\
\text { land }(\%)\end{array}$ & $\begin{array}{c}\text { Urbanized } \\
\text { land }(\%)\end{array}$ & Geologic units \\
\hline Wark & Ettelbruck & 81.5 & 24 & 30 & 42 & 4 & SH, SS \\
Schwebich & Useldange & 30.0 & 16 & 51 & 31 & 2 & SS, MR \\
Attert & Useldange & 247 & 29 & 35 & 32 & 4 & SH, MR, SS \\
Wiltz & Winseler & 102 & 34 & 34 & 25 & 7 & SH \\
Eisch & Hagen & 49.8 & 41 & 35 & 18 & 6 & MR \\
Petrusse & Luxembourg & 44.9 & 12 & 42 & 22 & 24 & MR. SS \\
Alzette & Hesperange & 288 & 27 & 26 & 29 & 18 & LS, MR \\
Alzette & Pfaffenthal & 356 & 25 & 27 & 28 & 20 & LS, MR, SS \\
\hline
\end{tabular}

The rainfall observation network in the study areas has an average density of one instrument per $30 \mathrm{~km}^{2}$, with automatic rain gauges functioning since the mid-1990s, measuring at 15-min time interval.

For the present study, hourly data of rainfall, potential evaporation and discharge have been used. Average rainfall for each sub-basin was determined using Thiessen polygons. An hourly time step has been selected because some of the selected basins show a fast reaction to rainfall, with concentration times in the order of a few hours.

Daily estimates of potential open water evaporation and potential transpiration were calculated using the PenmanMonteith equations, using temperature, wind speed, humidity and net radiation. The necessary data were measured at the meteorological station located at Luxembourg airport. Hourly estimates have been calculated distributing the daily amounts through a sinus function.

For model calibration 3 years of available records have been used, starting from 1 September 2001 until 31 August 2004. We regard this period as representative for the general hydrologic behaviour of the catchments studied, and particularly for the low flow behaviour, being the summer of 2003 one of the hottest and driest ever recorded in central Europe.

\section{Model description}

\subsection{FLEX model structure}

The Flex (Flux Exchange) hydrological model is a lumped conceptual model that represents the relevant hydrological processes occurring in the catchments.

The model is composed of four reservoirs: an interception reservoir $(I R)$, which takes into account the interception process, an unsaturated soil reservoir $(U R)$, which represents the storage capacity of the soil, a fast reacting reservoir $(F R)$ accounting for the formation of fast runoff components and a slow reacting reservoir $(S R)$, representing the slow runoff components (Fig. 2).

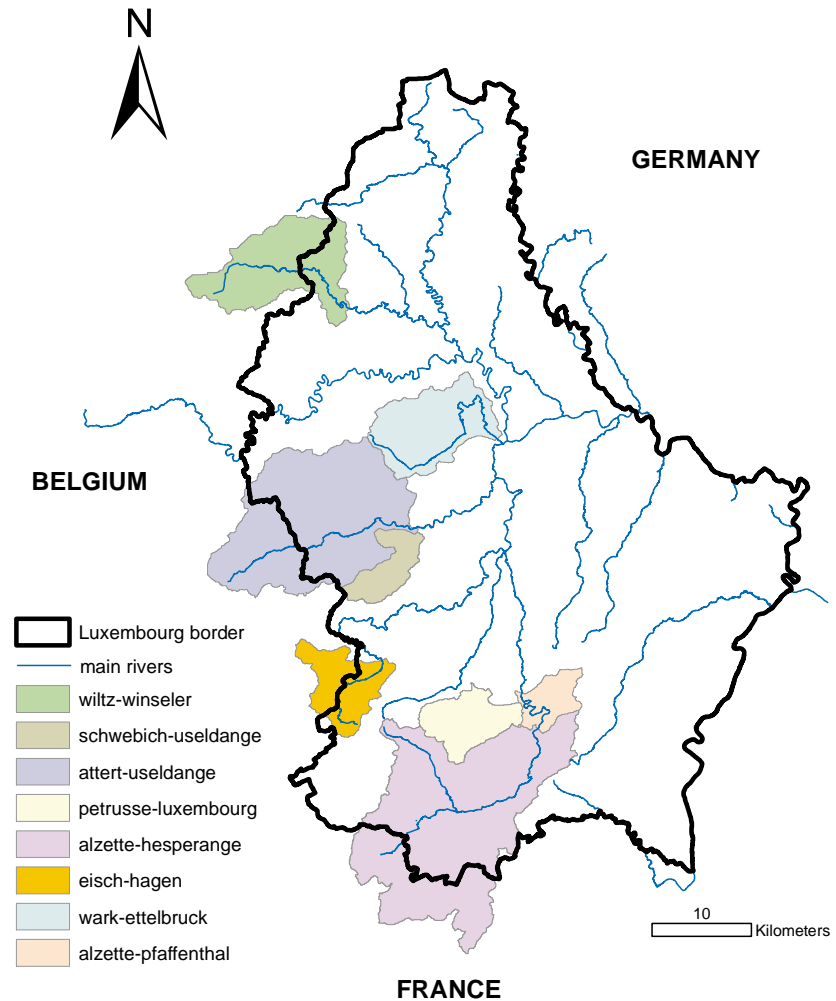

Fig. 1. Location of the subcatchments in the Grand-Duchy of Luxembourg.

\subsection{Interception module}

Rainfall reaches the $I R$, which can be filled up to a specified threshold, represented by $I_{\max }$. Evaporation from intercepted water $E_{i}$ can occur as long as water is available in the reservoir, and it is assumed to be linearly related to the potential evaporation $E_{p}$ through the coefficient $I_{c}$ :

$E_{i}=I_{c} \cdot E_{p}$ 


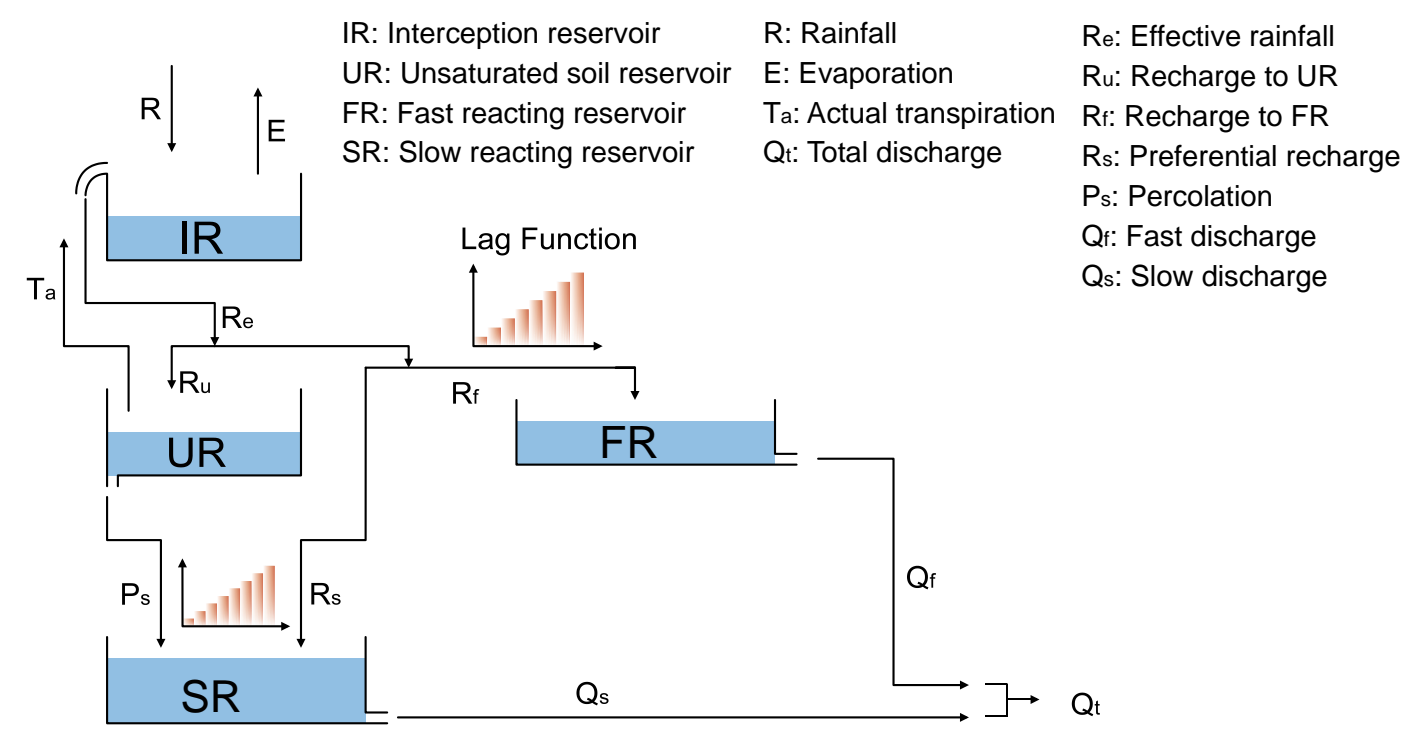

Fig. 2. Structure of the FLEX hydrological model.

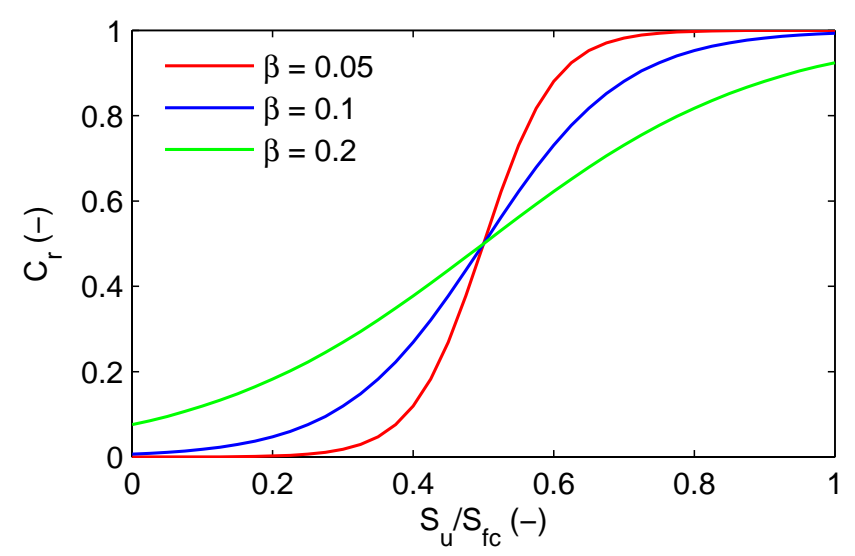

Fig. 3. $\mathrm{C}_{r}-\mathrm{S}_{u}$ functional relationship.

\subsection{Unsaturated soil module}

Effective rainfall $R_{e}$ leaves the $I R$ when the threshold $I_{\max }$ is exceeded. This amount is then partitioned into various components based on the value of an effective (i.e. after subtraction of interception, see: Savenije, 2004) runoff coefficient $C_{r}$ (Eq. 2), expressed as an S-shaped function dependent on the ratio between the storage $S_{u}$ and the maximum storage $S_{f c}$ of the $U R$ (Fig. 3). Part of $R_{e}$ infiltrates into the $U R$ $\left(R_{u}\right)$, excess water from the $U R$ is partitioned through the coefficient $D$ into preferential recharge $R_{s}$, which flows to the $S R$, and surface runoff $R_{f}$, which enters the $F R$ (Eqs. 3, $4,5)$.

$$
\begin{aligned}
C_{r} & =\frac{1}{1+\exp \left(\frac{-S_{u} / S_{f c}+1 / 2}{\beta}\right)} \\
R_{u} & =\left(1-C_{r}\right) \cdot R_{e}
\end{aligned}
$$

Percolation $P_{S}$ from the $U R$ to the $S R$ is calculated as a linear function of $S_{u}$ through the coefficient $P_{\max }$.

$P_{s}=P_{\max }\left(S_{u} / S_{f c}\right)$

The potential transpiration is converted into actual transpiration according to the following formula:

$T_{a}=T_{p} \cdot \min \left(1, \frac{S_{u}}{S_{f c}} \cdot \frac{1}{L_{p}}\right)$

Where $L_{p}$ is the fraction of $S_{f c}$ below which $T_{p}$ is constrained by $S_{u}$.

\subsection{Transfer routine}

As shown in Fig. 2, the transfer routine of the model consists of two lag functions and two reservoirs. The two lag functions are characterized by a triangular distribution of linearly increasing weights and are defined by the parameters $N_{\text {lagf }}$ and $N_{\text {lags }}$ that determine the number of time steps in the transformation routine. Those functions are used to offset the fluxes $P_{S}$ and $R_{S}$ that enter the $S R$ and the flux $R_{f}$ that enters the $F R$ and mainly control the lag-time of the system and the simulation of the rising limbs of the hydrograph.

The $F R$ is a linear reservoir defined by the time scale $K_{f}$, and the $S R$ is characterized by a S-D relation to be determined. The drainage equations for the two recession components can be expressed as:

$Q_{f}=S_{f} / K_{f}$

$Q_{s}=f\left(S_{s}\right)$

Where $Q_{f}$ and $Q_{s}$ are the fast and slow discharges and $S_{f}$ and $S_{s}$ are the storages of the $F R$ and $S R$, respectively. 


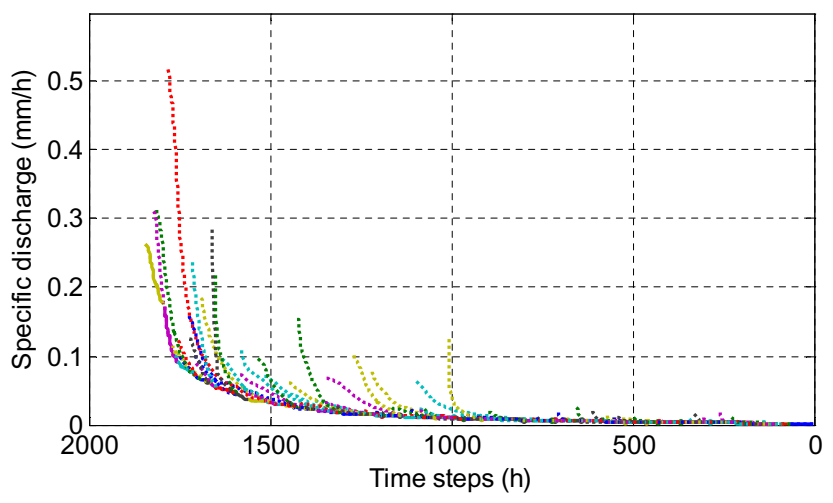

Fig. 4. Graphical representation of a Master Recession Curve (represented by the continuous line) for the Wark catchment.

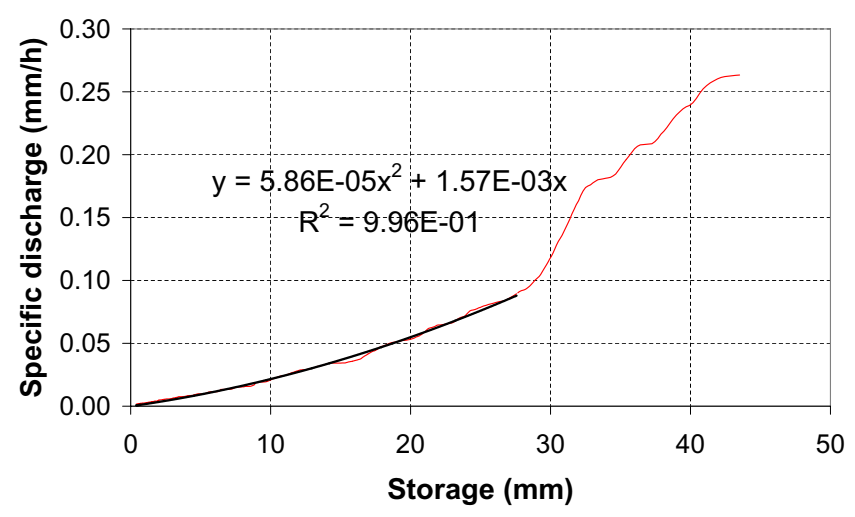

Fig. 5. Initial estimate of the storage-discharge relation.

These reservoirs mainly control the simulation of the recession limbs of the hydrograph. This simple transfer module is characterized by parameters that affect different aspects of the hydrograph, and goes in the direction of trying to ensure an orthogonal character of model parameters with respect to the objective functions used during their calibration.

The model has a total of 10 parameters that are summarized in Table 2 together with their corresponding units, and an unknown functional relationship (Eq. 9).

\section{Calibration of low flows}

The objective of the calibration procedure is to develop an optimal parameter set and an optimal derivation of the SD relation within the $S R$. The procedure is separated into two different stages (Hogue et al., 2000). In a first stage all model parameters and the unknown functional relation are calibrated to fit hydrograph recessions and low flows. In a second stage parameters that mostly influence high flows are recalibrated to give a better fit to the high portions of the hydrograph. This way we reach a solution that reflects system behaviour both in terms of high and low flows.
Table 2. Model parameters, units and physical limits.

\begin{tabular}{cccc}
\hline Parameter & Units & Range & Definition \\
\hline$I_{c}$ & - & $>0$ & Evaporation coefficient \\
$I_{\max }$ & $\mathrm{mm}$ & $>0$ & Interception threshold \\
$S_{f c}$ & $\mathrm{~mm}$ & $>0$ & Maximum $U R$ storage \\
$L_{p}$ & - & $0-1$ & Limit for potential transpiration \\
$\beta$ & - & $>0$ & Shape parameter of runoff generation \\
$D$ & - & $0-1$ & Runoff partition coefficient \\
$P_{\max }$ & $\mathrm{mm} / \mathrm{h}$ & $>0$ & Maximum percolation rate \\
$N_{\text {lagf }}$ & $\mathrm{h}$ & $>0$ & Lag-time of $F R$ transfer function \\
$N_{\text {lags }}$ & $\mathrm{h}$ & $>0$ & Lag-time of $S R$ transfer function \\
$K_{f}$ & $\mathrm{~h}$ & $>0$ & $F R$ time scale \\
\hline
\end{tabular}

The first calibration stage is composed of four steps that are hereafter described. The methodology is demonstrated by means of an application to the Wark catchment. Calculations in other catchments follow the same procedure.

\subsection{Step 1: Calculation of a Master Recession Curve}

The first step aims at providing an average characterization of the catchment response during recession periods. This is obtained by calculating a Master Recession Curve (MRC), which is constructed through an envelope of various individual recessions. A large number of methods exist for calculating the MRC (e.g. Sujono, 2004); among them we selected the automatic matching-strip method proposed by Lamb and Beven (1997).

The procedure uses all recession periods that are longer than a specified threshold and combines them into one synthetic recession curve (Fig. 4). The individual recession segments are sorted in ascending order based on the tail-end discharge values. The curve with the lowest tail-end discharge value is shifted over time until it overlaps with the next curve. The concatenation proceeds until the recession curve with the highest tail-end value is encountered. The purpose of this particular concatenation procedure is to exclude storm flow effects from the MRC. The MRC is therefore a synthetic curve that captures the long-term recession of the catchment over a wide range of flows. The lower ranges of this recession can hence be held to represent the discharge produced by the depletion of the "groundwater reservoir", here regarded as that portion of the catchment that sustains the slow hydrograph component.

In this case study, a threshold of $50 \mathrm{~h}$ has been selected as a minimum length for recession segments. Variations around this value did not appear to have a significant impact on the final MRC. The method allows the use of two filters to exclude recession periods associated with high rainfall volumes or high potential evaporation estimates. Those filters have not been used. Since we are interested in the lower discharges, we assume that in those periods a rainfall filter is already implicitly taken into account in the calculation of the MRC. If 


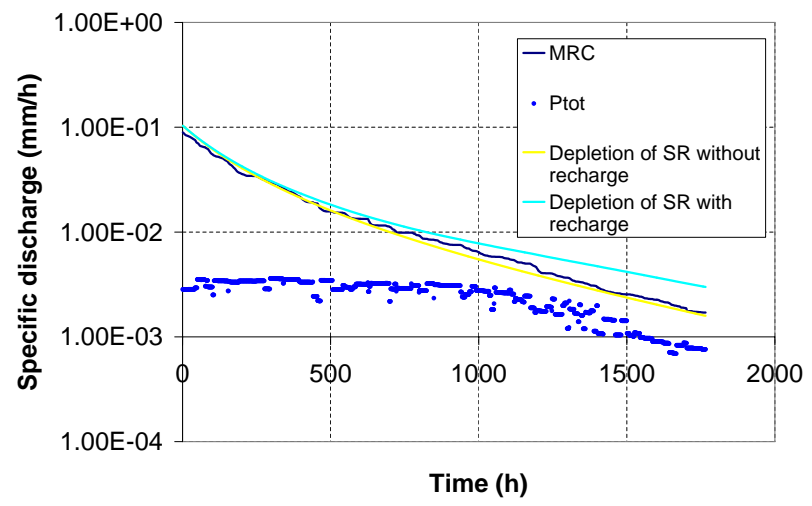

Fig. 6. Master recession curve, total recharge to the $\mathrm{SR}\left(\mathrm{P}_{t o t}\right)$ and recession curves from the SR with the initial (biased) S-D relation.

in those periods, characterized by a flat recession, a rainfall event has a significant impact on the observed hydrograph, it will determine an increase of discharge, and will therefore interrupt a recession period. Rainfall events that do not cause this effect are either very local, or produce an amount of water that is mostly intercepted by vegetation or by the first centimetres of soil.

The evaporation filter has not been used because in a wet climate and for the physiographic conditions of the catchment, where the groundwater table is mostly located far below the soil surface, we assume that the groundwater depletion due to water uptake caused by deep-rooted vegetation is, if not negligible, largely compensated by groundwater recharge from unsaturated soil drainage. This choice is consistent with the model structure used, which does not conceptualize a transpiration process from the $S R$.

For the subsequent analysis, it is necessary that the MRC decreases until zero (or negligible) discharge. If the MRC does not decrease up to this point, we assume that the flow behaviour below the range of observation is consistent with a reasonable extrapolation of the MRC. In this example we used linear extrapolation of the last $500 \mathrm{~h}$ of the MRC.

\subsection{Step 2: Initial estimate of the storage-discharge relation}

As the objective of a calibration procedure is to obtain a model that correctly simulate the processes for which they are designed, during low flow recession the $S R$ should empty in a way that matches the recession curve. The S-D relation characterizing the behaviour of the $S R$ should therefore be determined to match the MRC.

A first estimate of the S-D relation is calculated under the initial assumption that during periods of low flow, recharge to the $S R$ is negligible. Therefore, during these periods, there would be no inflow to the $S R$, and the outflow from the $S R$ is represented by the MRC.

The S-D relation is calculated by integration of the MRC over time, starting at the point of zero discharge and proceed- ing backward (Fig. 5). The choice for a certain extrapolation method to extend the MRC beyond the range covered by observations (see Sect. 4.1) has a negligible impact on the S-D relation since the total volume discharged during the extrapolation period is very small.

In order to obtain a curve in parametric form, the S-D relation calculated by integration of the MRC is described by an appropriate trend line. Since the calculated S-D relation presents an inflection point (Fig. 5), we decided to use only the portion of the curve below this point. This decision is justified considering that the MRC represents the flow recession over a wide range of flows, therefore, only the lower part of this curve can be assumed to characterize the groundwater flow, while the upper part is likely to include contributions from near surface flow.

The choice of an appropriate trend line to fit the S-D relation can be regarded as the choice of an appropriate model to represent the groundwater reservoir. Usual models include the linear reservoir (Malliet, 1905), the exponential reservoir, originally adopted in the TOPMODEL concept (Beven and Kirby, 1979), and the power-law reservoir (Tallaksen, 1995). Arbitrarily complex functions can be selected depending on specific cases. In this example we described the S-D relation with a second order polynomial function.

\subsection{Step 3: Calibration of other model parameters}

Once the drainage equation (Eq. 9) has been fixed, other model parameters can be calibrated. Parameter values are estimated through a single objective calibration procedure, choosing an objective function that emphasizes the simulation of low flows (Hogue et al., 2000):

$N_{L F}=\frac{1}{n}\left(\sum_{i=1}^{n}\left(\ln Q_{s, i}-\ln Q_{o, i}\right)^{2}\right)$

where

$n$ : total number of time steps

$Q_{s, i}:$ simulated flow for the time step i

$Q_{o, i}:$ observed flow for the time step i

Due to the use of the logarithmic function, the error (absolute difference between observed and simulated discharge) in simulating low flows weighs heavier than the error in simulating high flows. Calibrating model parameters to minimize $\mathrm{N}_{L F}$ therefore constrains the simulation of the lower portions of the hydrograph.

As a search method to identify the global optimum in the parameter space we have selected the Adaptive Cluster Covering (ACCO) strategy with local search developed by Solomatine $(1995,1999)$, which proves to be effective and efficient in global optimization problems. This algorithm is implemented in the global optimization tool GLOBE (Solomatine, 1999), which has been configured to calibrate the parameters of the FLEX model. 


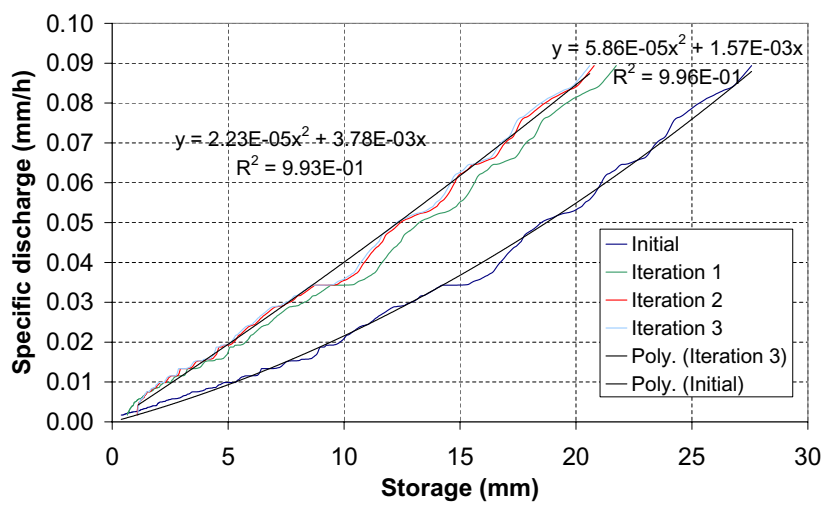

Fig. 7. Recalculation of the storage-discharge relation.

\subsection{Step 4: Recalculation of the storage-discharge relation}

In step 2 the $S-D$ relation for the $S R$ has been calculated under the assumption that no flux enters the $S R$ during low flow recessions. However, the $S R$ is recharged by percolation $\left(P_{S}\right)$ and by preferential recharge $\left(R_{S}\right)$. We define $P_{\text {tot }}$ as the total recharge to the $S R$, given by the lag-transformation of the sum of $P_{S}$ and $R_{S}$.

To assess the possible impact of $P_{t o t}$ on flow recession, we computed $P_{t o t}$ in correspondence of the time periods associated with the recession segments that compose the MRC; this time series is defined as $\boldsymbol{P}_{\text {tot }}$. Subsequently, we calculate the recession generated by depletion of the $S R$ with initial storage corresponding to the inflection point of Fig. 5 both in the case of absence of recharge, and in the case of recharge represented by $\boldsymbol{P}_{\text {tot }}$ (Fig. 6). In both cases, the $S R$ is characterized by the $S$-D relation previously determined (in absence of recharge).

Figure 6 shows that the first curve matches well with the MRC, while the second, which represents the behaviour of the model in operational conditions, differs from it substantially. In particular, the presence of recharge increases the water level of the $S R$ continuously, causing a slower (flatter) recession. This visual comparison shows that the impact of recharge on flow recession is not negligible. The initially calculated S-D relation determining the behaviour of the $S R$ therefore is biased, and has to be recalculated to take into account the effect of recharge.

The new estimate of the S-D relation is determined taking into account the inflow to $S R$. This procedure is the same as in step 2, with the difference that the storage is now calculated as the time integral of the difference between the outflow from the $S R$ (represented by the MRC) and the inflow (represented by $\boldsymbol{P}_{\text {tot }}$ ). The updated S-D relation is shown in Fig. 7 (iteration 1). We see that the recalculated curve is steeper than the initial one, meaning that, in order to match the MRC, the $S R$ has to empty faster than estimated initially. As in step 2, the recalculated S-D relation is approximated with an appropriate trend line, and applied to represent Eq. (9). Fig-

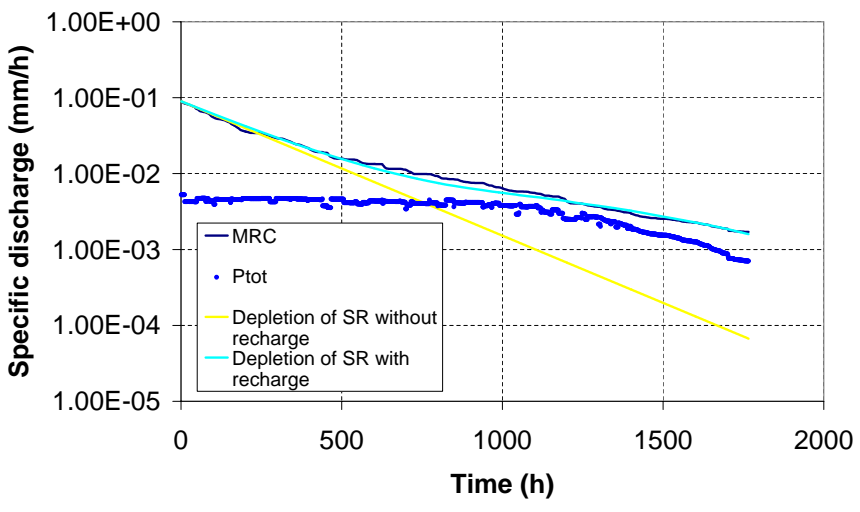

Fig. 8. Master recession curve, total recharge to the $\mathrm{SR}\left(\mathrm{P}_{t o t}\right)$ and recession curves from the $\mathrm{SR}$ with the final (actual) S-D relation.

ure 7 shows only the lower ranges of the S-D relations, as calculated in Fig. 5.

After a new S-D relation has been calculated, steps 3 and 4 are iterated until convergence is obtained in the determination of the $S-D$ relation. Convergence is considered to be reached when the relative difference of the total amount of flux entering the $S R$ (represented by the integral of $\boldsymbol{P}_{\text {tot }}$ over its time extent) in two successive iterations does not differ more than $10 \%$. The value of $10 \%$ may seem high, but takes into account that different calibration runs may give slightly different parameter estimates due to parameter equifinality (Beven, 1993). In this example, as shown in Fig. 7, only three iterations were necessary to reach convergence. We can see that the S-D relations for the 2 nd and 3rd iterations are already very close, giving a visual confirmation that the value of $10 \%$ chosen as a convergence criterion serves the purpose. For all other catchments, three to five iterations were sufficient.

The recession curves corresponding to the final (actual) $\mathrm{S}-\mathrm{D}$ relation are shown in Fig. 8. The steeper curve represents the depletion of the $S R$ in absence of recharge. The flatter curve represents the depletion of the $S R$ in presence of recharge (represented by $\boldsymbol{P}_{\text {tot }}$ ) and characterizes the behaviour of the $S R$ in operational conditions. This curve now matches reasonably well the MRC.

The hydrograph simulation after the application of the iterative procedure is represented in Fig. 9. We see that the discharge produced by the $S R$ matches well the lower ranges of the flow recession, while the higher ranges are approached by the contribution of the FR. The time period shown in the figure includes the highest discharge simulated by the $S R$. As it is possible to notice, the range of discharges simulated by the $S R$ corresponds to the range of the S-D relation that we assumed to be sustained by groundwater (Fig. 5).

In Fig. 7 the initial and final estimates of the S-D relation are shown, together with the respective trend lines. From the figure it is evident that the two curves are different, meaning 


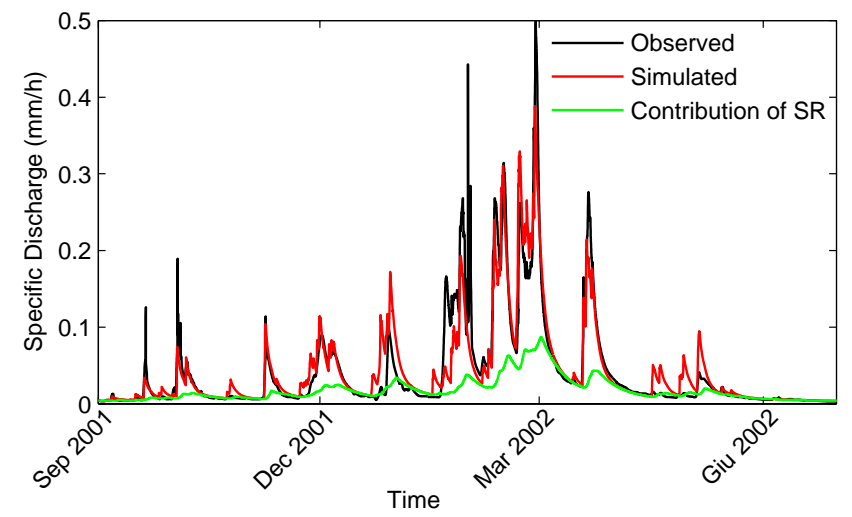

Fig. 9. Hydrograph representation after the application of the iterative procedure (Wark catchment).

that it is necessary to go through the iterative procedure to determine the actual S-D relation, representative of the observed groundwater behaviour during recession periods. We can also see clearly that the relation tends to become linear after the application of the iterative procedure, which also appeared to be the case in the other catchments. This point will be discussed further in Sects. 6 and 7.

The iterative procedure has been demonstrated for a particular model, which, apart from being developed to represent what we assume to be the dominant processes of the region studied, has been configured to facilitate the process of inferring from data the behaviour of the $S R$. Some consideration regarding the peculiarities of this procedure and some suggestions to apply the methodology to other situations are given.

- In the FLEX model, the transfer functions are applied to the inflow of the recession reservoirs and not to the outflow, as in other commonly used model structures (e.g. the HBV model, Lindström et al., 1997). This obviously facilitates the calculation of the S-D relation from the MRC. A transfer function applied to the outflow of the $S R$ would bias this flux, making this operation more complicated.

- A possible way to overcome this problem in other model structures (such as the HBV) would be to avoid the use of a transfer function for the flux flowing through the reservoir that aims at simulating the slow hydrograph components, or to offset the flux entering the reservoir, instead of the outflow.

- Some conceptual hydrological models do not consider continuous percolation from the soil moisture compartment to the groundwater compartment (e.g. the HBV model). In the FLEX model this could be realized by setting the flux $P_{s}$ to zero. In this situation only the flux $R_{S}$ would remain to feed the $S R$. This flux is mostly related to rainfall events, and can therefore be consid- ered to occur in time periods associated with the rising limbs of the hydrograph. In this case there would be no recharge to the $S R$ during recession periods, and there is therefore no need to modify the S-D relation calculated in step 2 through the iterative procedure shown in this section. This is a possibility that would allow some simplifications in the calibration phase and allows applying the S-D relation extracted from the data directly in the structure of the model. However in this case we have observed that this simplification, while allowing a fairly good representation of flow recessions, diminishes the overall performance of the model.

- The structure of the model is developed according to the perception of the dominant processes present in the catchment studied. With reference to the exchanges of the groundwater reservoir, the structure conceptualizes the process of unsaturated soil drainage, and preferential recharge. Capillary rise has not been included because the dominant flux is considered to be directed downward. Model tests including this process seemed to confirm this consideration, meaning that this flux was automatically set to zero through the calibration process. However, in more arid climates, capillary rise may be a dominant process. The same applies to other fluxes from and to the groundwater aquifer (e.g., groundwater leakage, or transpiration from deep-rooted vegetation). Such processes can be easily included in the present model structure. The iterative procedure can therefore be easily extended to those cases, and used to analyze the impact of such fluxes (measured or simulated) on flow recession.

- The success in the convergence of the S-D relation mostly depends on the parameter idenfiability (Wagener et al., 2003) of the model. Lack of identifiability of model parameters defining the recharge to the $S R$ would have resulted in large differences of simulated recharge from one iteration to another, making convergence unlikely.

\section{Calibration on high flows}

If the aim is to obtain a full rainfall-runoff model, one should continue improving the faster components while keeping the slow compartment unaltered. The association of model parameters with specific hydrograph characteristics is in general not a simple task, but can be less problematic with models that are developed focusing on the hydrological processes that dominate the hydrologic behaviour of a catchment, such as in this case. Those models are in fact developed in a way that their components aim at simulating essential features of a given catchment response to hydrologic events. The corresponding parameters can therefore be related to specific hydrograph characteristics. 

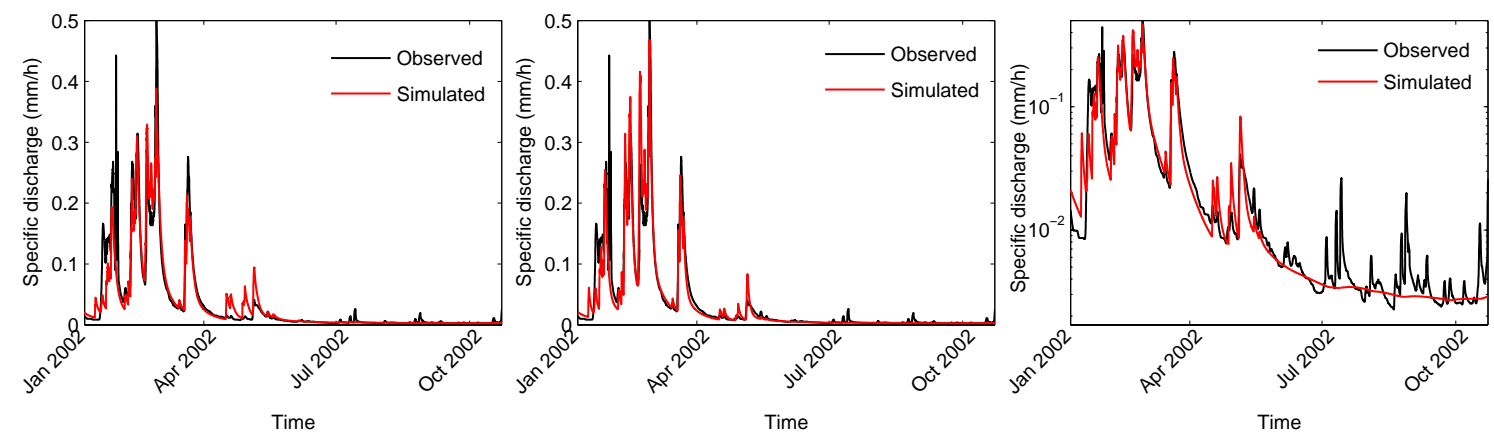

Fig. 10. Effect of recalibration of high flow related parameters.

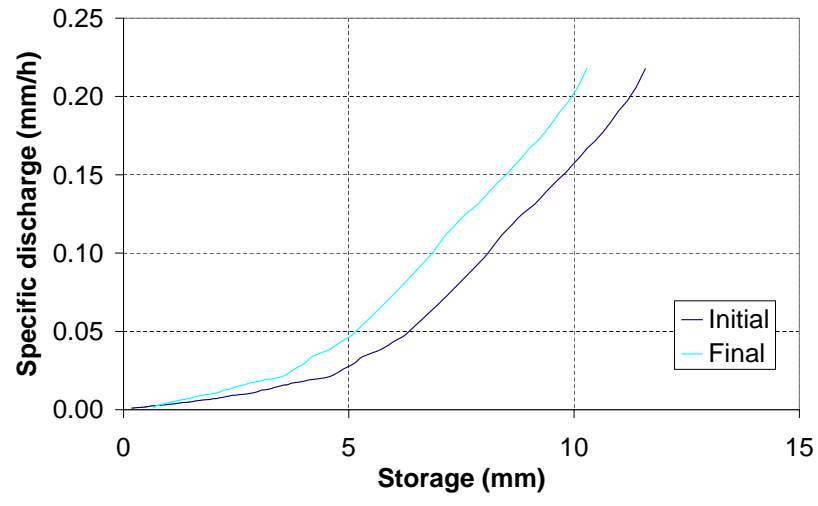

Fig. 11. Storage-discharge relation for the Petrusse catchment.

We consider the parameters related to the parameterization of the $U R$ and the $F R$ and the parameter representing the length of the transfer function that offsets the flux entering the $F R$ as mostly related to the representation of high flows. Therefore these parameters can be recalibrated to match the high flow portions of the hydrograph, after the slow compartment has been fixed. Here, the recalibration procedure has been applied to the following parameters: $S_{f c}, L_{p}, \beta$, $N_{\text {lagf }}$ and $K_{f}$. Interception-related parameters were not recalibrated because it is assumed that the effect of interception on the hydrograph is better identifiable during periods of low flow. Peak discharges are less affected by interception, whereas the storage accumulation driving groundwater recession is.

The selected parameters are readjusted to minimize the objective function $N_{H F}$ represented by the following equation:

$N_{H F}=\frac{1}{n}\left(\sum_{i=1}^{n}\left(Q_{s, i}-Q_{o, i}\right)^{2}\right)$

Compared to $N_{L F}, N_{H F}$ puts a stronger weight on the error occurring in high flows, due to the square of the difference between observed and simulated discharge.

The evolution of the value of parameters and objective functions in the two successive calibration stages is shown in
Table 3. Evolution of model parameters and objective functions in successive calibration stages.

\begin{tabular}{cccc}
\hline Parameter & Units & LF calibration & HF calibration \\
\hline$I_{c}$ & - & $1.32 \mathrm{E}+0$ & \\
$I_{\max }$ & $\mathrm{mm}$ & $5.13 \mathrm{E}+0$ & \\
$S_{f c}$ & $\mathrm{~mm}$ & $4.27 \mathrm{E}+2$ & $3.86 \mathrm{E}+2$ \\
$L_{p}$ & - & $1.00 \mathrm{E}+0$ & $1.00 \mathrm{E}+0$ \\
$\beta$ & - & $3.37 \mathrm{E}-2$ & $1.35 \mathrm{E}-2$ \\
$D$ & - & $3.37 \mathrm{E}-1$ & \\
$P_{\max }$ & $\mathrm{mm} / \mathrm{h}$ & $1.04 \mathrm{E}-2$ & \\
$N_{\text {lagf }}$ & $\mathrm{h}$ & $5.01 \mathrm{E}-1$ & $5.14 \mathrm{E}+0$ \\
$N_{\text {lags }}$ & $\mathrm{h}$ & $6.41 \mathrm{E}+1$ & \\
$K_{f}$ & $\mathrm{~h}$ & $4.81 \mathrm{E}+1$ & $3.27 \mathrm{E}+1$ \\
& & & \\
Objectives & & & $2.99 \mathrm{E}-1$ \\
$N_{L F}$ & - & $2.55 \mathrm{E}-1$ & $1.06 \mathrm{E}-3$ \\
$N_{H F}$ & - & $1.22 \mathrm{E}-3$ & \\
\hline
\end{tabular}

Table 3. The effect of recalibrating high flow related parameters results in an improvement of $N_{H F}$, and in a deterioration of $N_{L F}$. Figure 10 illustrates the effect of the calibration procedure on the hydrograph simulation for the Wark catchment. The first graph represents the calibration after the first calibration stage; the second and third graphs show the effect of recalibration in the second calibration stage. The third graph is the same as the second but plotted on a log scale to enhance flow recession and low flows. We can see that the recalibration of high flow related parameters improves the simulation of high flows, while the representation of low flows and flow recession remains almost unaltered. It is also noticeable from the second and third graph that the overall performance of the model is quite good, and the trend of the observed recession is maintained. In the third graph, the peaks in the tail are enhanced by the logarithmic scale, but, as shown on the normal scale they are relatively small, and could be caused by rain on surface water (or rain on saturated banks or on impervious areas) which this simple model doesn't consider. 
Table 4. Linearity of the storage-discharge relation.

\begin{tabular}{lcc}
\hline Catchment & $\mathrm{R}^{2}$ initial & $\mathrm{R}^{2}$ final \\
\hline Wark & 0.97 & 0.99 \\
Schwebich & 0.86 & 0.95 \\
Attert & 0.91 & 0.96 \\
Wiltz & 0.99 & 0.99 \\
Eish & 0.97 & 0.98 \\
Petrusse & 0.79 & 0.87 \\
Alzette-Hes & 0.95 & 0.98 \\
Alzette-Pfaf & 0.96 & 0.97 \\
\hline
\end{tabular}

It is also noticeable that, notwithstanding a linear storagedischarge relation, the simulated recession does not plot as a straight line on a semi-logarithmic scale. The recession in fact becomes nonlinear due to the effect of recharge.

\section{Results from the 8 catchments in Luxembourg}

The same procedure has been applied to the other selected catchments. In all cases we observed that the final estimate of the S-D relation tends to be more linear than the initial estimate, calculated from data alone. The linearity of this relation is evaluated by fitting the curves with a linear trend line, and calculating the coefficient of determination $\mathrm{R}^{2}$. The interpolation concerns the portion of the S-D relation that is below the maximum discharge generated by the $S R$ during the model simulations.

From Table 4 we conclude that all catchments show an increase of linear behaviour of the S-D relation, suggesting that the apparent overall nonlinear behaviour can be (at least partly) explained as a biasing effect of recharge. From Table 4 it can be seen that the final values of $R^{2}$ are quite high for almost all catchments, showing that in most cases a linear reservoir, as part of the configuration of the model used, is suitable to simulate the groundwater response. The only exception is in the Petrusse catchment, whose initial and final $\mathrm{S}-\mathrm{D}$ relations are represented in Fig. 11. The reason why this catchment behaves differently from the others may lie in the fact that, unlike the other catchments, it is not a natural catchment anymore. The Petrusse catchment is highly urbanised (Table 1) with artificial drainage and sewerage. The sewer system (draining a continuous stream of household waste water) strongly influences the base flow, and alters the natural discharge especially during periods of low flows. It is also interesting to notice that the Alzette-Pfaffenthal catchment, which includes the Petrusse, does not appear to be affected by the influence of the Petrusse catchment. This is because the Petrusse catchment is only a small fraction of the AlzettePfaffenthal, and its contribution to the total stream discharge is relatively small.

\section{Discussion: is the groundwater reservoir linear?}

While the objective of this study is to calibrate a conceptual model to streamflow data, making use of the typical behaviour of a recession curve to model the groundwater reservoir in a catchment, we come to the conclusion that a linear reservoir (subject to recharge) can very well describe the groundwater behaviour of the catchments studied. This fuels a further discussion regarding the general validity of the linear groundwater reservoir in conceptual modelling.

The concept of a linear groundwater reservoir was first introduced by Malliet (1905) and is still widely used in conceptual modelling. The linear model assumes that the storage is linearly proportional to the outflow, namely, $S=k Q$, where $k$ is defined as the time scale of the process, which can be considered to represent average residence time in storage. Theoretical studies of groundwater flow have shown that a linear storage-discharge relationship describes the groundwater behaviour of one-dimensional flow in a confined aquifer with constant thickness and uniform hydraulic conductivity (Werner and Sundquist, 1951).

Numerical analyses of streamflow recessions show that the simple linear reservoir model does not satisfactory represent the recession curve over a wide range of flows (Tallaksen, 1995); the catchment storage should therefore be given a nonlinear representation, or be modelled by more than a single reservoir. Nonlinear storage-discharge relationships have also been analytically derived, considering aquifers in various configurations (Moore, 1997; Chapman, 1999). The linear reservoir model, however, is generally recognized as being a good approximation in most practical situations (Chapman, 1999).

While inferring the behaviour of the groundwater reservoir from recession data it is normally assumed that the groundwater flow is the only outflow from the groundwater reservoir, and that during recession periods no recharge to the saturated zone takes place. However, it must be kept in mind that other fluxes to and from the aquifer may be present, which can influence significantly the shape of flow recessions. Such fluxes include evaporation from the riparian zone, transpiration from deep-rooted vegetation, capillary rise to the vadose zone, groundwater abstractions, groundwater leakage, and recharge from the unsaturated zone. These fluxes may lower (or increase) the storage of the groundwater reservoir continuously, causing steeper (or flatter) recession curves. When those fluxes are neglected, the integration of the observed recession results in a biased storage-discharge relationship, which does not represent the actual storagedischarge relationship that characterizes the behaviour of the groundwater reservoir.

The effect of evaporation and transpiration on flow recession were shown to be significant in arid and semi-arid conditions (Wittemberg and Sivapalan, 1999). Similarly, in temperate and humid climates, the effect of recharge from unsaturated soil or perched aquifers may have a considerable 
impact on flow recession. The impact of this flux is obviously very difficult to quantify, and it is often neglected in recession analyses.

In this work, with the intention of optimising the parameterization of a model reservoir conceptualizing the groundwater processes, we use internal model results to quantify the impact of this flux on flow recession, and we show that the actual storage-discharge relationship characterizing the model reservoir differs from what was initially estimated from discharge data alone. In particular, due to the presence of recharge, in order to match the observed recessions, the model reservoir has to empty faster than initially estimated, and the storage-discharge relation becomes more linear.

Because of model structural uncertainties and model parameter uncertainties, model internal results cannot be regarded as a measure of the physical processes occurring in reality. It is not even among the objectives of this study to provide such a measure.

However the outcomes of this study offer a possible explanation for the often-observed non-linear behaviour of the groundwater reservoir. Many studies in fact reported that the recession constant $k$ of the linear model is not constant in observed low flow recessions, but decreases with the increase of discharge, indicating a nonlinear process (Wittemberg, 2003; Moore, 1997; Chapman, 1999). Chapman (1999) explains this phenomenon as a consequence of the convergence of flow lines in the groundwater system. The results of this work suggest that this effect could be explained as a consequence of recharge. For the higher discharges the impact of recharge on recession is low, because the recharge is only a small fraction of the total outflow during that period (see Fig. 6). But for low discharges, the effect of recharge can become significant, producing a flatter recession curve.

The hypothesis that the groundwater reservoir is continuously recharged also during recession periods by drainage from the unsaturated soil or from perched aquifers appears plausible in the Luxembourg region, which is characterized by a humid-temperate climate. However, further research and alternative measures should be used to confirm or invalidate this hypothesis, and to quantify the effect of this flux.

Ultimately, a question remains concerning a possible explanation to the pattern observed worldwide indicating that the groundwater reservoir of a catchment often shows a simple behaviour, while the reality is known to be complex and heterogeneous. The storage-discharge relationship of a catchment is in fact often well described by simple analytical functions, such as the exponential, power law, and often linear. Those functions can be analytically derived for aquifers in very simple configurations and under crude approximations (e.g. homogeneous isotropic medium) that contrast with the complexity and heterogeneity that are often observed in nature. Still, those relations appear to work well in most situations.

An explanation of this evidence may lie in the concept of self-organization. The dynamic organization and interac- tion of complex small-scale processes can demonstrate order at larger scales that can be described by general principles and simple laws (Savenije, 2001). This effect is often observed in nature, and concerns several branches of research, from climate to cells, organisms, ecosystems and economies (Kleidon and Lorenz, 2005). It can be regarded as a result of the tendency of a complex system to produce the maximum amount of disorder (entropy). In this view, enlarging the scale of application, the system contains a larger number of microscopic arrangements that tend to average out, and its global behaviour from chaotic and unpredictable becomes regular and ordered.

Rodriguez-Iturbe and Rinaldo (1997) show how the landscape evolution can be explained on the basis of the principle of minimum energy expenditure and maximum entropy production (as a measure of disorder). We can hypothesize that the process of self-organization that leads to the formation of river basin landscapes also applies underground, modelling the subsurface drainage network, and leading to a simple (often linear) behaviour of the groundwater reservoir.

In this view, instabilities, hystereses, strong nonlinearities in the storage-discharge relation characterizing the groundwater behaviour can be regarded as a consequence of the scale of application chosen (too small for the natural averaging to take place), or of artificial activities influencing the natural flow regime, or of relatively young geological formations where the self-organization of the natural environment has not yet fully developed.

\section{Conclusions}

In this study we propose a methodology that aims at calibrating a conceptual rainfall-runoff model to streamflow data. The methodology develops an optimal parameter set and an optimal derivation of the storage-discharge relationship characterizing the behaviour of the model reservoir that simulates the slow hydrograph component.

The procedure used to determine this relationship can be regarded as a combination of a top-down and bottom-up approach. A first estimate of this relation is in fact calculated integrating the master recession curve, which is determined analysing discharge data alone. This relation is subsequently iteratively improved by taking into account the impact of model internal fluxes (in particular, modelled recharge of groundwater) on flow recession.

Model calibration is performed stepwise: in a first stage all parameters and the storage-discharge relation are calibrated towards a bias to low flows, subsequently, model parameters designed to influence the simulation of high flows are recalibrated with a bias to high flows. This way we reach a model configuration that performs well both during low flows and during high flows. The methodology is applied to a specific model structure; however, it could be easily adapted to other commonly used conceptual models as well. In this work, we 
cast the calibration problem in an optimization framework, and no parameter uncertainty analysis is performed.

The paper contains the results of the tests of this methodology on several catchments in Luxembourg, representative of the variability of conditions of this area. With respect to the parameterization of the reservoir that simulates the slow hydrograph component, we determined that in general a linear model can well represented well the groundwater behaviour of the catchments. The non-linearity observed in the storagedischarge relation derived from data alone, appeared to be explained as a bias produced from groundwater recharge. This result is obviously influenced by the specific test conditions, including model structure, calibration methodology, data quality and availability, as well as all the subjective assessments made by the user (e.g. choice of a specific model to represent the groundwater behaviour). Hence, further research is needed to allow a more reliable quantification of the impact of groundwater recharge on flow recession.

Acknowledgements. We thank the "Public Research Center Gabriel Lippmann" of Luxembourg and the "Administration de la Gestion de l'Eau" for making available the data used in study.

Edited by: E. Zehe

\section{References}

Ambroise, B., Beven, K., and Freer, J.: Toward a generalization of the TOPMODEL concepts: topographic indices of hydrological similarity, Water Resour. Res., 32(7), 2135-2145, 1996.

Beven, K. J.: Prophesy, reality and uncertainty in distributed hydrological modelling, Adv. Water Res., 16, 41-51, 1993.

Beven, K. and Kirby, M. J.: A physically-based variable contributing area model of basin hydrology, Hydrol. Sci. Bull., 24, 303325, 1979.

Boyle, D. P., Gupta, H. V., and Sorooshian, S.: Towards improved calibration of hydrologic models: Combining the strengths of manual and automatic methods, Water Resour. Res., 36, 36633674, 2000.

Chapman, T.: A comparison of algorithms for stream flow recession and baseflow separation, Hydrol. Processes, 13, 701-714, 1999.

Grayson R. and Blöschl, G. (Eds.): Spatial Patterns in Catchment Hydrology: Observations and Modelling, Cambridge University Press, Cambridge, UK, 2000.

Gupta, H. V., Sorooshian, S., and Yapo, P. O.: Toward improved calibration of hydrologic models: Multiple and noncommensurable measures of information, Water Resour. Res., 34(4), 751-763, 1998.

Hogue, T. S., Sorooshian, S., Gupta, H., Holz, A., and Braatz, D.: A Multi-step Automatic Calibration Scheme for River Forecasting Models, J. Hydrometeorol., 1, 524-542, 2000.

Kleidon, A. and Lorenz, R. D. (Eds.): Non-Equilibrium Thermodynamics and the Production of Entropy: Life, Earth, and Beyond, Springer, Heidelberg, 2005.

Klemeš, V.: Conceptualization and scale in hydrology, J. Hydrol., 65, 1-23, 1983.

Lamb, R. and Beven, K. J.: Using interactive recession curve analysis to specify a general catchment storage model, Hydrol. Earth Syst. Sci., 1, 101-113, 1997.
Lindström, G., Johansson, B., Persson, M., Gardelin, M., and Bergström, S.: Development and test of the distributed HBV-96 hydrological model, J. Hydrol., 201, 272-288, 1997.

Maillet, E.: Essais d'Hydraulique Souterraine et Fluviale, Hermann, Paris, 218 pp, 1905.

Moore, R. D.: Storage-outflow modelling of streamflow recessions, with application to a shallow-soil forested catchment, J. Hydrol., 198, 260-270, 1997.

Nathan, R. J. and McMahon, T. A.: Evaluation of automated techniques for base flow and recession analyses, Water Resour. Res., 26(7), 1465-1473, 1990.

Rodriguez-Iturbe, I. and Rinaldo, A.: Fractal River Networks: Chance and Self-Organization, Cambridge University Press, New York, 1997.

Savenije, H. H. G.: Equifinality, a blessing in disguise?, Hydrol. Processes, 15, 2835-2838, 2001.

Savenije, H. H. G.: The importance of interception and why we should delete the term evapotranspiration from our vocabulary, Hydrol. Processes, 18(8), 1507-1511, 2004.

Seibert, J. and McDonnell, J. J.: On the dialog between experimentalist and modeler in catchment hydrology: use of soft data for multicriteria model calibration, Water Resour. Res., 38(11), 1241, doi:10.1029/2001WR000978, 2002.

Sivapalan, M., Blöschl, G., Zhang, L., and Vertessy, R.: Downward approach to hydrological prediction, Hydrol. Processes, 17, 2101-2111, 2003.

Solomatine, D. P.: The use of global random search methods for model calibration, in: Proc. XXVIth Congress of IAHR (London, September 1995), vol. 1, 224-229. Thomas Telford Ltd., London, UK, 1995.

Solomatine, D. P.: Two strategies of adaptive cluster covering with descent and their comparison to other algorithms, J. Global Optimiz., 14, 55-78, 1999.

Sujono, J., Shikasho, S., and Hiramatsu, K.: A comparison of techniques for hydrograph recession analysis, Hydrol. Processes, 18, 403-413, 2004.

Tallaksen, L. M.: A review of baseflow recession analysis, J. Hydrol., 165, 349-370, 1995.

Uhlenbrook, S. and Leibundgut, C.: Process-oriented catchment modelling and multiple-response validation, Hydrol. Processes, 16, 423-440, 2002.

Wagener, T., Boyle, D. P., Lees, M. J., Wheater, H. S., Gupta, H. V., and Sorooshian, S.: A framework for the development and application of hydrological models, Hydrol. Earth Syst. Sci., 5, 13-26, 2001.

Wagener, T., McIntyre, N., Lees, M. J., Wheater, H. S., and Gupta, $\mathrm{H}$. V.: Towards reduced uncertainty in conceptual rainfall-runoff modeling: dynamic identifiability analysis, Hydrol. Processes, 17(2), 455-476, 2003.

Werner, P. W. and Sundquist, K. J.: On the groundwater recession curve for large watersheds, in IASH General Assembly, Brussels, IAHS Publ., 33, 202-212, 1951.

Wittenberg, H. and Sivapalan, M.: Watershed groundwater balance estimation using stream-flow recession analysis and baseflow separation, J. Hydrol., 219, 20-33, 1999.

Wittenberg, H.: Effects of season and man-made changes on baseflow and flow recession; case studies, Hydrol. Processes, 17, 2113-2123, 2003. 